\title{
SCIENTIFIC REPORTS

\section{Reactive Extraction of Malic Acid using Trioctylamine in 1-Decanol: Equilibrium Studies by Response Surface Methodology Using Box Behnken Optimization Technique}

Victoria Inyang* \& David Lokhat

Reactive extraction is a significant technique employed for the removal of organic acids such as carboxylic acid which are usually present in low concentrations in aqueous solutions. This technique was explored by applying Response Surface Methodology (RSM) in process parameter optimization for malic acid recovery from aqueous streams using Trioctylamine as extractant and 1-decanol as organic diluent. Malic acid, a $\mathrm{C}_{4}$ dicarboxylic acid has a wide variety of applications in the polymer, food, chemical and pharmaceutical industries. The optimization of the response function: extraction efficiency was systematically carried out using three process parameters for reactive extraction: temperature, initial malic acid concentration and extractant (Trioctylamine) composition. Response Surface Methodology in combination with Box-Behnken design involving seventeen experimental runs was employed for malic acid reactive extraction in this study. A statistical second-order polynomial predicted an extraction efficiency of $97.53 \%$. The optimum conditions of the process variables were found to be: temperature: $304.73 \mathrm{~K}$, acid concentration: $0.25 \mathrm{kmol} / \mathrm{m}^{3}$, Trioctylamine composition: $23.54 \%(\mathrm{v} / \mathrm{v})$. Under these optimum conditions, the experimental response of extraction efficiency of $93.25 \%$ was obtained. The experimental results obtained was in close conformity with the predicted values by numerical optimization using Response Surface Methodology. These findings can pave the way for the reactive separation process design for recovery of carboxylic acids from dilute aqueous waste streams as well as a fermentation broth.

Carboxylic acids are usually present in low concentrations in aqueous stream. Interest in the recovery of these acids from dilute aqueous solutions with acid concentrations lower than $10 \%(\mathrm{w} / \mathrm{w})$, has received considerable attention ${ }^{1}$. Most recent research is targeted at carboxylic acid separation process selection with low material consumption and less energy requirement in the downstream processing. An intensified process that satisfies these requirements is reactive separation since significant improvements are achieved in both stages of reaction and separation. Carboxylic acids such as butyric acid, lactic acid, propionic acid, malic acid are useful bulk chemicals for several industries. Malic acid is a $\mathrm{C}_{4}$-dicarboxylic acid and also an intermediate of the tricarboxylic acid cycle. It has a variety of applications in polymer, food, chemical and pharmaceutical industries ${ }^{2}$. The downstream recovery technique for carboxylic acids accounts for $30-50 \%$ of the overall production $\operatorname{cost}^{3,4}$. Hence, the current interest in finding a more cost-effective recovery technique. Reactive extraction is a significant technique for the separation of important carboxylic acids which leads to a high solute distribution coefficient as a result of combining physical and chemical phenomena ${ }^{5}$. The factors that are favourable for carboxylic acids reactive extraction include an existing functional group which increases capacity and selectivity in solute molecules, a high driving force of complexing agents as a result of low concentration and low volatility of the solute ${ }^{6}$. The application of reactive extraction to different carboxylic acid from dilute aqueous solution has been successfully carried out; such as; Latic acid ${ }^{7,8}$, Itaconic acid ${ }^{9,10}$ Succinic acid ${ }^{11,12}$, Levulinic acid ${ }^{13,14}$, pyruvic acid ${ }^{15}$ tartaric acid $^{16}$, propionic acid ${ }^{17-19}$. The appropriate solvent selection as constituents of the organic phase is an underlining factor for 
high distribution coefficient and extraction efficiency. High viscous extractants for example phosphorus bonded, oxygen-bearing and hydrocarbon, high molecular weight aliphatic amines with diluents are often employed in the carboxylic acid reactive extraction process for improvement of physical properties such as interfacial surface tension and viscosity ${ }^{1,20}$.

In general; there are primary, secondary and tertiary amines in amine-type extractants. Among these amines, the tertiary amines offer better advantage in reactive extraction because the primary and secondary amines tend to react irreversibly with carboxylic acids and therefore, the stripping of solvent becomes difficult ${ }^{21}$. Reactive extraction using long-chain aliphatic tertiary amines (anion exchange extractants such as trioctylamine) with seven to nine carbon atoms in each alkyl group has been studied as the most effective, efficient and widely employed extractants for carboxylic acids. When dissolved in different modifiers (solvents), they are powerful extractant reagents for the carboxylic acids ${ }^{22}$. They provide high extraction efficiency $(>90 \%)$ and are less expensive as compared with the oxygen donor or phosphorus-based extractants ${ }^{8}$. These extractants used in the reactive extraction processes in organic acid separation can be recycled thus making them effective and efficient. Ratchford, et al. ${ }^{23}$ studied the effects of amine structure and the solvent properties. The solvation of the whole amine-acid complex is based on dipole-dipole interaction and has been found to play a key role in the neutralization reaction between acid and amines. Amine-based extractants are highly favourable for carboxylic acid extraction, for example, the citric acid process was technically feasible using tertiary amine extractant ${ }^{24}$. In addition to high efficiency and selectivity, they provide for product concentration through extraction at about ambient temperatures. These extractants are often used with an organic solvent as diluent which has a significant effect on the extraction performance, acid loading and stoichiometric association ${ }^{25-28}$. The diluent may consist of one or more components, inert or active. Various active polar and proton or electron-donating diluents (halogenated aliphatic/aromatic hydrocarbons, ketones, nitrobenzenes, higher alcohols), enhance the extraction. On the other hand, inert diluents (long-chain paraffin, benzene etc.), limit the extractant capacity ${ }^{1029,30}$. Significantly, diluents with a moderate polarity such as a long chain or higher alcohols (for example 1-octanol and 1-decanol) greatly improves the solvation power of the acid-amine complex. They also influence the basicity of the amine and improve phase separation and the stability of the ion-pair (acid-amine complex) formed. Thus preventing third phase formation which limits the extraction ability giving a high distribution coefficient ${ }^{8}$. Significant research studies have been conducted on the influence of diluents on amine extractants in carboxylic acids recovery ${ }^{26,28,31,32}$. With this background, 1-decanol with moderate polarity, water-insoluble diluent and less toxic has been considered in the present study. And so, TOA in combination with 1-decanol has been chosen for this work as effective extractant and diluent respectively.

Several studies have been conducted on the reactive extraction process on organic acid separation from fermentation aqueous waste stream. However, studies which employ statistical technique on the experimental design of malic acid recovery from aqueous solution using an intensified process such as reactive liquid-liquid separation process is limited in the literature. The selection of a suitable technique for evaluating different process parameter is important as well as any interactions involved while minimizing the number of experimental runs. This research study is centered on the application of Box Behnken in data analysis, optimizing process parameters and exploring appropriate conditions to be employed in the reactive extraction process for optimal extraction efficiency and distribution coefficient.

The study intends to enhance the extraction yield for effective and efficient recovery of malic acid from dilute aqueous solution by employing trioctylamine as extractant mixed with high polarity solvent, 1-decanol as diluent. Also, the major factor influencing the reactive extraction process include temperature, the concentration of the extractant and acid. This work is also aimed at analysing, optimizing and finding appropriate conditions of these process variables using response surface method (RSM) by employing a Box-Behnken design to maximize the efficiency of the malic acid reactive extraction process (\% E). The statistical design of experiment is used for process parameter optimization for the malic acid extraction to prevent drawbacks obtained from classical methods. The optimum parameters of the intensified reactive extraction process will be used to determine the reaction rate kinetics of the extraction process. Response surface methodology (RSM) is an effective tool for statistical design of experiments, model development and for finding complex processes to optimize the target yield (s). It is also a statistical tool used to create a link between a set of defined experimental variables and the observed results. The adopted stepwise procedure in this study is as shown (Fig. 1).

\section{Results and Discussion}

The experimental data was analyzed using Response Surface Methodology (RSM) to examine the combined effects of temperature, malic acid concentration and TOA composition and the results are reported (Table 1). Analysis of Variance (ANOVA) was employed to predict the correlation between independent process variables and the corresponding responses and a second-order polynomial equation was obtained for extraction efficiency of malic acid and is presented in "Eq. (1)".

$$
\mathrm{E} \%=79.28+6.63 X_{1}+7.93 X_{2}-24.4 X_{3}+1.18 X_{1} X_{2}+4.15 X_{1} X_{3}+7.35 X_{2} X_{2}-12.12 X_{1}^{2}-11.16 X_{2}^{2}+5.94 X_{3}^{2}
$$

where the variable $X_{1}=$ temperature, $X_{2}=$ Acid concentration and $X_{3}=$ TOA concentration.

The regression model and ANOVA of extraction efficiency for reactive extraction of malic acid using TOA in 1-decanol are presented (Table 2). From the Table, the model F-value of 67.66 indicates the model is significant. There is only a $0.01 \%$ chance that an F-value this large could occur due to noise. Values of "Prob $>$ F" less than 0.0500 indicate model terms are significant. In this case, $X_{1}, X_{2}, X_{3}, X_{1}^{2}, X_{2}^{2}, X_{3}^{2}$ are significant model terms. Also, values of "Prob $>$ F" greater than 0.1000 indicate the model terms are measured as insignificant. The coefficient of correlation with lower P values are considered to to be more important. The correlation coefficient values (R2) was adequate $(0.9886)$ for the response $(\mathrm{P} \leq 0.05)^{33}$. The plots of the correlation coefficient and the adjusted values 


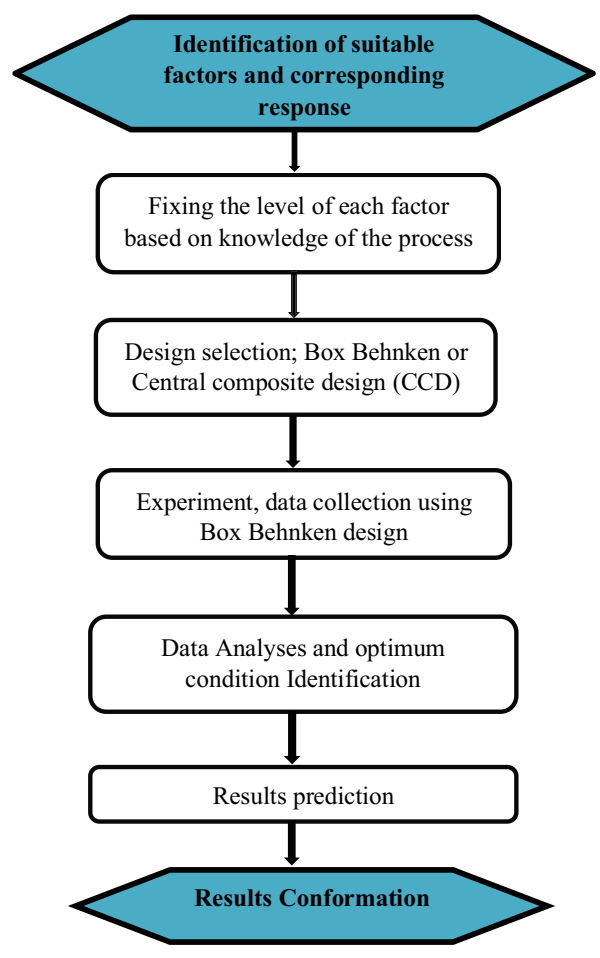

Figure 1. RSM step-wise procedures adopted in the study.

\begin{tabular}{|c|c|c|c|c|c|}
\hline \multirow[b]{3}{*}{ Std } & \multirow[b]{3}{*}{ Run } & \multirow{2}{*}{$\begin{array}{l}\text { Factor } 1 \\
\text { Temperature }\end{array}$} & \multirow{2}{*}{$\begin{array}{l}\text { Factor } 2 \\
\text { TOA Composition }\end{array}$} & \multirow{2}{*}{$\begin{array}{l}\text { Factor } 3 \\
\text { Acid Concentration }\end{array}$} & \multirow{2}{*}{\begin{tabular}{|l|} 
Response 1 \\
Extraction \\
Efficiency
\end{tabular}} \\
\hline & & & & & \\
\hline & & $\mathbf{K}$ & $\% \mathrm{v} / \mathrm{v}$ & $\mathrm{kmol} / \mathrm{m}^{3}$ & $\% \mathrm{E}$ \\
\hline 10 & 1 & 0.000 & 1.000 & -1.000 & 98.571 \\
\hline 1 & 2 & -1.000 & -1.000 & 0.000 & 39.307 \\
\hline 3 & 3 & -1.000 & 1.000 & 0.000 & 53.030 \\
\hline 16 & 4 & 0.000 & 0.000 & 0.000 & 79.264 \\
\hline 7 & 5 & -1.000 & 0.000 & 1.000 & 40.750 \\
\hline 9 & 6 & 0.000 & -1.000 & -1.000 & 97.619 \\
\hline 5 & 7 & -1.000 & 0.000 & -1.000 & 98.571 \\
\hline 11 & 8 & 0.000 & -1.000 & 1.000 & 34.833 \\
\hline 14 & 9 & 0.000 & 0.000 & 0.000 & 79.307 \\
\hline 17 & 10 & 0.000 & 0.000 & 0.000 & 79.394 \\
\hline 4 & 11 & 1.000 & 1.000 & 0.000 & 75.030 \\
\hline 12 & 12 & 0.000 & 1.000 & 1.000 & 65.191 \\
\hline 6 & 13 & 1.000 & 0.000 & -1.000 & 97.143 \\
\hline 13 & 14 & 0.000 & 0.000 & 0.000 & 79.091 \\
\hline 2 & 15 & 1.000 & -1.000 & 0.000 & 56.606 \\
\hline 8 & 16 & 1.000 & 0.000 & 1.000 & 55.917 \\
\hline 15 & 17 & 0.000 & 0.000 & 0.000 & 79.351 \\
\hline
\end{tabular}

Table 1. Experimental design of variables (coded) for malic acid extraction efficiency E\%.

for comparing the model fitness is presented (Fig. 2). The adequate precision value which measures single to noise ratio is expected to be greater than 4 . The model ratio gotten in this work is 24.866 which indicates an acceptable signal and can be employed to pilot the design space. The variation coefficient obtained is relatively low $(\mathrm{CV}=4.84 \%)$, which indicates the accuracy and reliability of the model. The contour plots and three dimensional (3D) graphs were generated as a result of the effects of the interaction between two independent variables on the response by maintaining one constant process variables at zero levels (coded) ${ }^{34}$.

Effect of the different variables on reactive extraction of malic acid. In order to access the effect of the different process variables on the extraction efficiency, experimental design of the single factor effect was 


\begin{tabular}{|c|c|c|c|c|c|c|}
\hline \multirow[b]{2}{*}{ Source } & \multirow{2}{*}{\begin{tabular}{|l|} 
Sum of \\
Squares
\end{tabular}} & \multirow[b]{2}{*}{ df } & \multirow{2}{*}{\begin{tabular}{|l} 
Mean \\
Square
\end{tabular}} & \multirow{2}{*}{$\begin{array}{l}\mathrm{F} \\
\text { Value }\end{array}$} & \multirow{2}{*}{\begin{tabular}{|l|} 
p-value \\
Prob $>$ F \\
\end{tabular}} & \multirow[b]{3}{*}{ significant } \\
\hline & & & & & & \\
\hline Model & 7207.38 & 9 & 800.82 & 67.66 & $<0.0001$ & \\
\hline$X_{1}$-Temperature & 351.61 & 1 & 351.61 & 29.71 & 0.0010 & \\
\hline$X_{2}$-TOA Concentration & 503.34 & 1 & 503.34 & 42.53 & 0.0003 & \\
\hline$X_{3}$-Acid Concentration & 4763.57 & 1 & 4763.57 & 402.49 & $<0.0001$ & \\
\hline$X_{1} X_{2}$ & 5.53 & 1 & 5.53 & 0.47 & 0.5164 & \\
\hline$X_{1} X_{3}$ & 68.85 & 1 & 68.85 & 5.82 & 0.0466 & \\
\hline$X_{2} X_{3}$ & 216.16 & 1 & 216.16 & 18.26 & 0.0037 & \\
\hline$X_{1}^{2}$ & 618.82 & 1 & 618.82 & 52.29 & 0.0002 & \\
\hline$X_{2}^{2}$ & 524.85 & 1 & 524.85 & 44.35 & 0.0003 & \\
\hline$X_{3}^{2}$ & 148.41 & 1 & 148.41 & 12.54 & 0.0095 & \\
\hline Residual & 82.85 & 7 & 11.84 & & & \\
\hline Lack of Fit & 82.79 & 3 & 27.60 & 2017.72 & $<0.0001$ & significant \\
\hline Pure Error & 0.055 & 4 & 0.014 & & & \\
\hline Cor Total & 7290.23 & 16 & & & & \\
\hline \multicolumn{7}{|l|}{$\begin{array}{l}\text { Std.Dev }=3.44 \\
\text { R-Squared }=0.9886\end{array}$} \\
\hline \multicolumn{7}{|l|}{$\begin{array}{l}\text { Mean }=71.12 \mathrm{Adj} \\
\text { R-Squared }=0.9740\end{array}$} \\
\hline $\begin{array}{l}\text { C.V.\%=4.84 Adeq } \\
\text { Precision }=24.866\end{array}$ & & & & & & \\
\hline
\end{tabular}

Table 2. Analysis of variance and response surface regression model for malic acid reactive extraction.

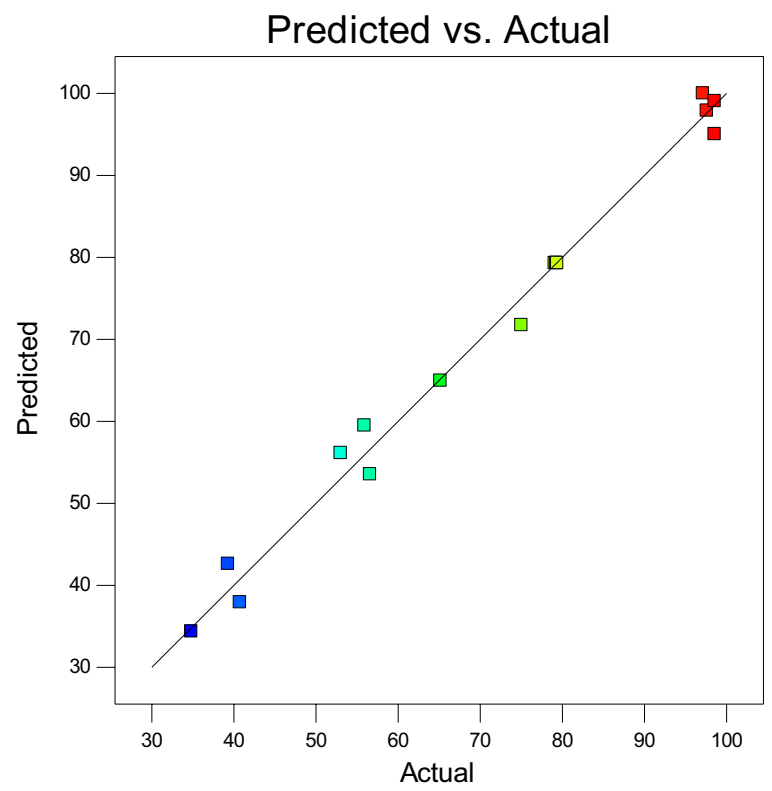

Figure 2. Predicted model plot against experimental extraction efficiency (\%E) from RSM Model.

adopted (one variable at a time). The three variables considered were temperature, initial acid concentration and trioctylamine composition. The experimental design was achieved by vaying one variable while holding the other two independent variable constant (see supplementary Table S1 and Figs. S1-S3).

The models selected has explained the combined effect of three variables on the malic acid extraction efficiency (\%E). The three dimensional (3D) graphs of the response surfaces and the corresponding contour lines map were necessary to explain the effects of the different process parameters as presented (Figs. 3, 4, 5). The experimental results illustrated (Fig. 3), presents the effects on the interaction between TOA composition and temperature on the extraction efficiency. It can be interpreted from the figure that extraction efficiency increases with an increase in extractant concentration $(10-30 \%, v / v)$ irrespective of the temperature. This might be a product of the increase in extractant concentration which increases the extractability of the extractant and further helps to reach extraction equilibrium and the ability to form a complex ${ }^{35}$. The complexation reactions at equilibrium occur at the organic-aqueous interface and is an exothermic process. The malic acid-TOA complex brings about orderliness in the reactive extraction process thus decreasing the randomness and entropy of the system. 

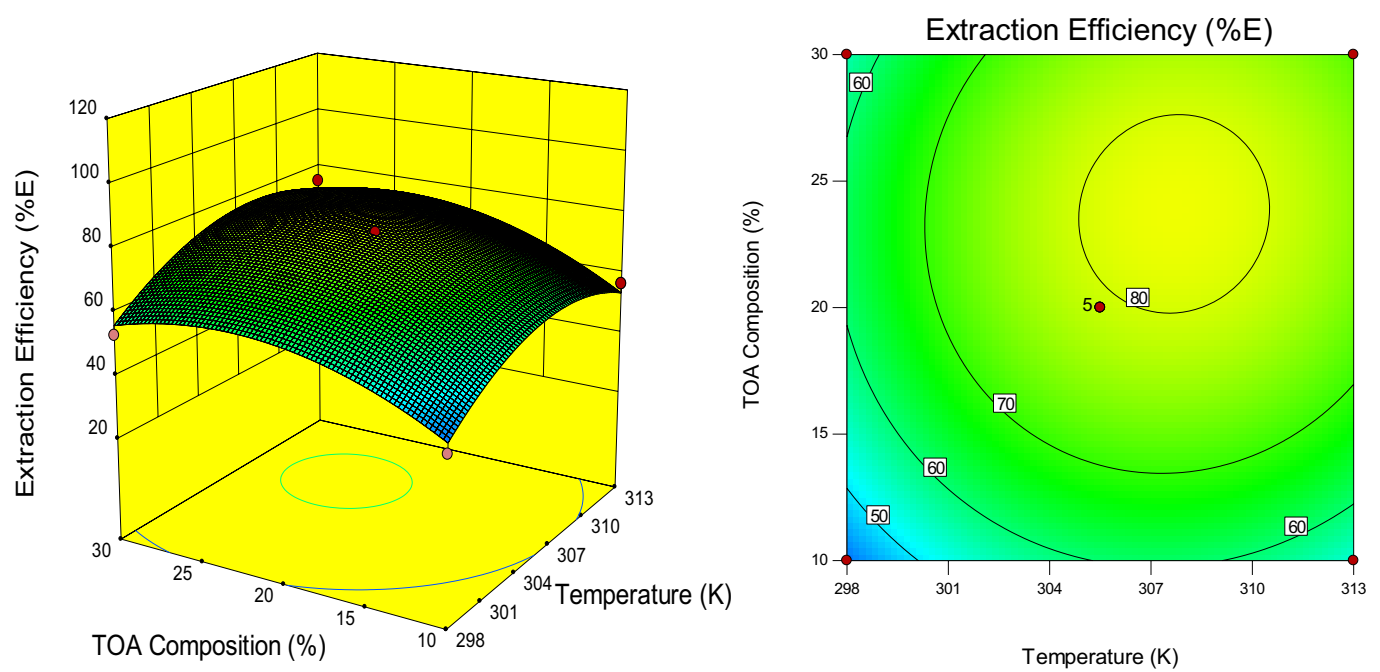

Figure 3. Response surface plot and a contour-lines map displaying the effects of interaction between TOA composition and temperature variables on extraction efficiency.
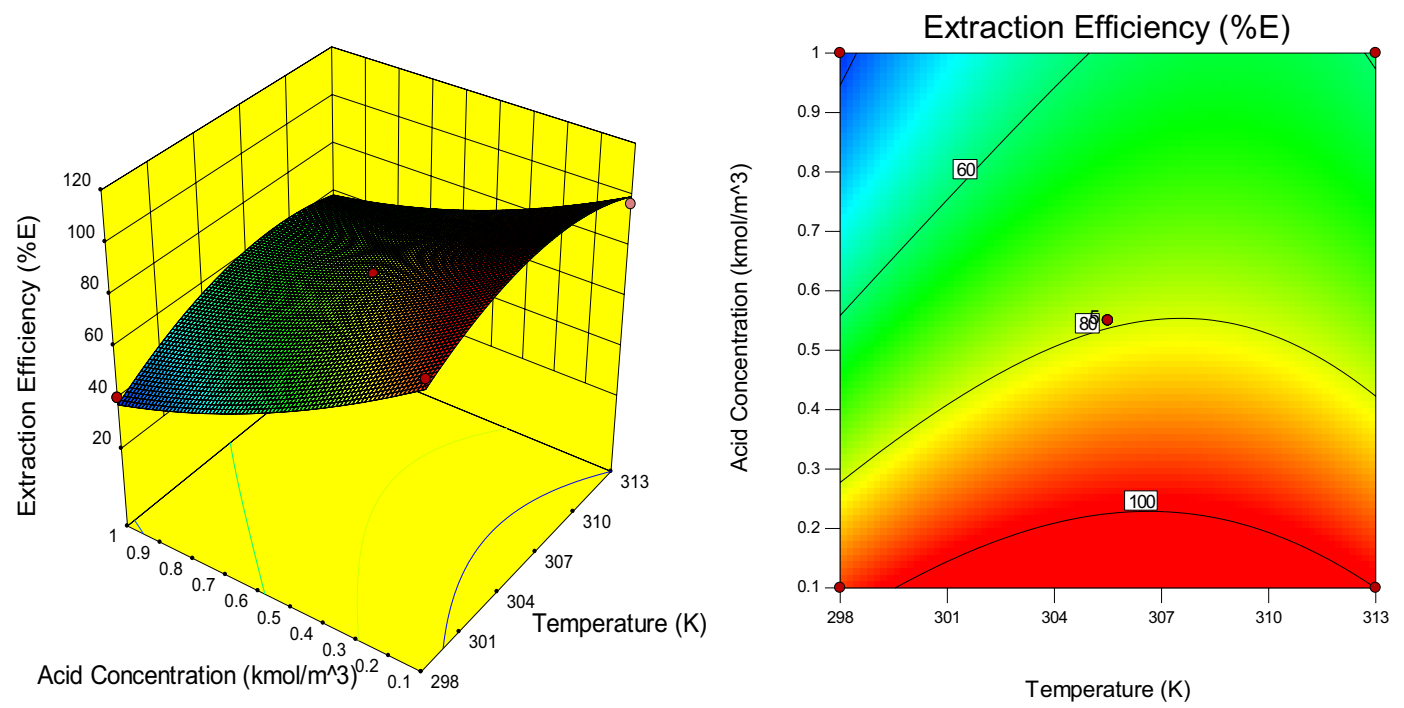

Figure 4. Response surface plot and a contour-lines map displaying the effects of interaction between acid concentration and temperature variables on extraction efficiency.

The temperature increase also increases the kinetic energy of the molecules thereby interrupting certain interactions and acid-amine molecule combinations to form a stable complex at the interface ${ }^{36}$. Another reason could be as a result of the exothermic reactions of the transfer of proton and formation of hydrogen bond which decreases the system entropy ${ }^{30}$.

The interactive effects of malic acid concentration and temperature on the extraction efficiency is elucidated (Fig. 4). It can be interpreted from the figure that the extraction efficiency decreased with an increase in malic acid concentration regardless of the temperature. This is because the tendency of extractant overloading increases with solute concentration ${ }^{37}$. The extraction efficiency decreases with a rise in acid concentration and on further temperature enhancement. This might be due to the disturbance of extractant and solute molecules interaction in the organic phase with thermal energy increase leading to a reduction in the formation of the complex ${ }^{38}$.

The extraction efficiency at a higher solvent ratio $(30 \%, \mathrm{v} / \mathrm{v})$ initially increases up to a certain point and then starts decreasing with further increase in acid concentration (Fig. 5). This might be because of the presence of 1-decanol, a polar organic solvent being reduced with an increase in extractant ratio owing to $\mathrm{H}$-bonding between $\mathrm{C}=\mathrm{O}$ of the acid-extractant complex and the proton of the polar diluent ${ }^{39}$.

Process variables optimization. The same software, design expert was employed in the numerical optimization of the process parameters to maximize the malic acid extraction efficiency. The predicted maximum values obtained from the model for the reactive extraction of malic acid for maximum extraction efficiency are 

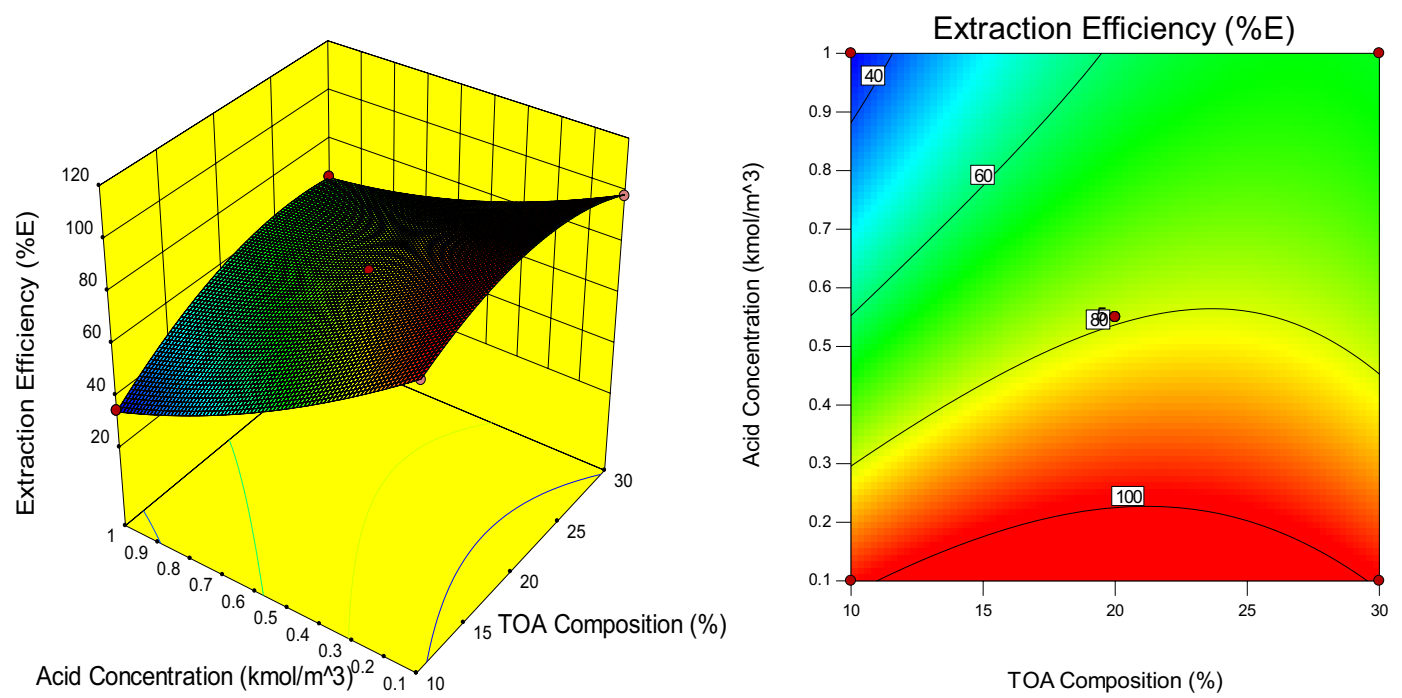

Figure 5. Response surface plot and a contour-lines map displaying the effects of interaction between acid concentration and TOA composition variables on extraction efficiency.

temperature: $304.73 \mathrm{~K}$, acid concentration: $0.247 \mathrm{kmol} / \mathrm{m}^{3}$, Trioctylamine composition: $23.54 \%(\mathrm{v} / \mathrm{v}$ ) and the model prediction for the extraction efficiency under these optimum conditions as $97.53 \%$. Experimental verification and validation were conducted at the optimized process variables and the results obtained (93.25\%) were in good agreement with the predicted model response values.

\section{Conclusion}

In this study, the reactive extraction of malic acid onto a biphasic organic-aqueous system with trioctylamine in 1-decanol as extractant and diluent respectively for determining the extraction efficiency and distribution coefficient was successfully carried out. Box Behnken design was employed to study the interactive effects of different process parameters on the equilibrium studies of malic acid. The regression analysis using ANOVA, experimental design and quadratic model was developed to predict and optimize the functional relationship between the process variables (temperature, malic acid concentration and extractant composition) and the response (extraction efficiency and distribution coefficient). The optimum conditions of the process variables were found to be: temperature: $304.73 \mathrm{~K}$, acid concentration: $0.247 \mathrm{kmol} / \mathrm{m}^{3}$, Trioctylamine composition: $23.54 \%$ (v/v). Under these optimum conditions, the experimental value for the extraction efficiency (E\%) was $93.25 \%$. These findings and results can pave the way for the reactive separation process design for recovery of carboxylic acids from dilute aqueous waste streams as well as a fermentation broth. This can unlock pathways to the recovery of these acids in low concentrations.

\section{Materials and Methods}

Experimental chemicals deployed. All the chemicals, Malic acid $\left(\mathrm{C}_{4} \mathrm{H}_{6} \mathrm{O}_{5}\right)$, density $1.61 \mathrm{~g} / \mathrm{mL}$, Trioctylamine (TOA), $\left[\mathrm{CH}_{3}\left(\mathrm{CH}_{2}\right)_{7}\right]_{3} \mathrm{~N}$, density $0.809 \mathrm{~g} / \mathrm{mL}$ and 1 -decanol, density $0.829 \mathrm{~g} / \mathrm{mL}$ deployed in this study at purity of $98 \%$ were purchased from Sigma-Aldrich and the experimental water was obtained using an Elga PURELAB Option Q purification system. Deionized water from our laboratory was used throughout the experiment. Phenolphthalein indicator and 0.1 M Sodium hydroxide were also purchased from Sigma-Aldrich. All chemicals were used as supplied with no further purification.

Equilibrium studies. Reactive extraction equilibrium studies were conducted by preparing $25 \mathrm{~mL}$ aqueous solution $\left(0.1 \mathrm{kmol} / \mathrm{m}^{3}\right.$ concentration of malic acid) and $25 \mathrm{~mL}$ organic phase solution was prepared by mixing $(10-30) \%$ of Trioctylamine extractant $(\% \mathrm{v} / \mathrm{v})$ equivalent to $\left(0.229-0.687 \mathrm{kmol} / \mathrm{m}^{3}\right)$ in 1 - decanol at temperatures between $(298-313 \mathrm{~K})$ in an orbital shaker which was placed in the oven for 5 hours at $120 \mathrm{rpm}$, the two phases was kept to settle for 2 hours. The aqueous phase analysis was carried out using the titration method with $0.1 \mathrm{~N}$ $\mathrm{NaOH}$ and phenolphthalein as an indicator to obtain malic acid concentration. The organic phase concentration of malic acid was determined through mass balance. The experimental runs were done in triplicate to confirm the reproducibility of results.

Experimental design and response surface methodology. The different experimental cycles were carried out using the design of experiment template obtained using Box-Behnken design (BBD) with three variables at three levels each in the optimization of the process variables used in the reactive extraction process. The Design-Expert version 10.0 (Statease Inc., Minneapolis, USA) was employed in this study. The un-coded (original) value of the different factors and their corresponding coded levels employed in the experimental design is as shown (Table 3).

There are three main stages in Response Surface Methodology which include: 


\begin{tabular}{|l|l|l|l|l|}
\hline & & Coded & Level & \\
Factors & Units & Values & Low & High \\
\hline Temperature & $\mathrm{K}$ & Factor $\mathrm{X}_{1}$ & 298 & 313 \\
\hline $\begin{array}{l}\text { Solvent Composition } \\
\text { (v/v) }\end{array}$ & $\%$ & Factor $\mathrm{X}_{2}$ & 10 & 30 \\
\hline Acid Concentration & $\mathrm{kmol} / \mathrm{m}^{3}$ & Factor $\mathrm{X}_{3}$ & 0.100 & 1.000 \\
\hline
\end{tabular}

Table 3. Range of different variables for reactive extraction of Malic acid.

i. Parameter selection and experimental design; finding a suitable estimation between independent process (factors) and the dependent (response) variables ${ }^{34}$.

ii. Modeling of the response obtained from experimental results through regression and analysis of variance.

iii. Response optimization; the optimum values of the independent process parameters; malic acid concentration, extractant ratio $(\% \mathrm{v} / \mathrm{v})$ and temperature $(\mathrm{K})$ were estimated to gain maximum value of the response, Extraction Efficiency (E\%).

The relationship established between coded $\left(\mathrm{x}_{\mathrm{i}}\right)$ and real $\left(\mathrm{X}_{\mathrm{i}}\right)$ value is represented in "Eq. (2)" as

$$
\text { Coded value }\left(\mathrm{x}_{\mathrm{i}}\right)=\frac{X_{i}-X_{0}}{\Delta X_{i}}, \mathrm{i}=1,2,3 \ldots \ldots, \mathrm{n}
$$

where $\Delta \mathrm{X}$ is the phase change and $\mathrm{X}_{0}$ is the real value at the center position

Taking into consideration all interactions of the input parameters (linear to linear and linear to quadratic), the behavior of the system can be described by "Eq. (3)".

$$
\mathrm{Y}=\beta_{0}+\sum_{i=1}^{n} \beta_{i} X_{i} \sum_{i=1}^{n} \beta_{i i} X_{i}^{2}+\sum_{i<j}^{n} \sum_{j}^{n} \beta_{i j} X_{i} X_{j}+\varepsilon
$$

where $\mathrm{I}$ and $\mathrm{j}$ are linear and quadratic coefficients respectively; $\mathrm{n}$ is the number of experimental parameters $(\mathrm{n}=3)$. $\beta_{0}$ is constant coefficient, $\beta_{i}$ is the linear outcome or slope of input factor, $\beta_{i i} X_{i}$ is a quadratic outcome of input factor $X_{i}$ and $\beta_{i j}$ is linear effect interaction between input factors $X_{i}$ and $X_{j}$, $\varepsilon$ is the residual error.

Theory of reactive extraction of Malic acid. The reactive extraction process for malic acid accounts for the combined effect of physical and chemical extraction. Physical extraction (dimerization and ionization) involves solute separation which is free of complexities. In physical extraction, factors responsible and considered according to some researchers ${ }^{9,18,40}$ are:

a. Aqueous phase ionization of Malic acid $\left(\mathrm{as} \mathrm{H}^{+} \mathrm{A}^{-}\right)$and its corresponding non-facilitated transportation to the organic phase.

$$
\begin{aligned}
& {[H A]_{a q} \leftrightarrow \mathrm{A}^{-}+\mathrm{H}^{+}} \\
& \text {Un-dissociated Malic acid Dissociated Malic acid }
\end{aligned}
$$

b. Equilibrium distribution and partial malic acid dissociation between phases

$$
\begin{aligned}
{[H A]_{a q} } & \leftrightarrow[H A]_{\text {org }} \\
\text { Un-dissociated Malic acid } & \text { Dissociated Malic acid }
\end{aligned}
$$

c. Organic phase acid dimerization

$$
2[H A]_{a q} \leftrightarrow[H A]_{\text {org }}^{2}
$$

Distribution coefficient is presented with respect to dimerization coefficients according to ${ }^{41}$ :

$$
\begin{aligned}
K_{D}^{\text {diluent }} & =P+2 P^{2} D[H A]_{a q} \\
\text { where } P & =[H A]_{\text {org }} /[H A]_{a q} \quad D=[H A]_{2, \text { org }} /[H A\}_{\text {org }}^{2}
\end{aligned}
$$

In chemical or reactive extraction (diffusion and solubility) of Malic acid, the process involved the contacting of a second phase extractant (trioctylamine and 1-decanol) that will reversibly react with the solute. The reaction with the liquid-liquid extraction which is attained in one unit operation may be interpreted in three steps. Initially, transportation of reactants to the interface forming aqueous-organic phase interface from the bulk and interaction with the molecules of extractant, thus the formation of extractant-acid complex and finally, the complex that is formed is transported unto the organic phase for removal of the malic acid ${ }^{42}$. To explain and describe the mechanism of chemical extraction using "Eq. (9)", the equilibrium constant according to 9 is presented in Equation as:

$$
\text { Solute }+ \text { n. Extractant } \leftrightarrow \text { Complex }
$$




$$
K_{c}=\frac{[\text { Complex }]}{[\text { Solute }][\text { Extractant }]^{n}}
$$

During the reactive extraction of malic acid, the three mechanisms of reaction involved (anion exchange, the formation of ion-pair and $\mathrm{H}$-bond) were noted due to the acid-extractant complex formation in the solution dependent upon trioctylamine (extractant) basicity and the constant of dissociation of the extracted species ${ }^{20}$. The complex formed will remain at the interface otherwise it will orient towards the interphase with any hydrophilic complexes formed in the organic phase ${ }^{43}$. When there exists any non-dissociated form of malic acid in the aqueous phase, the malic acid reaction with trioctylamine takes place through the formation of hydrogen bond leading to trioctylamine-malic acid complex formation of (1:1) and also (1:2), (1:3) at higher concentration of malic acid.

$$
\begin{aligned}
& R_{3} N+H A \leftrightarrow R_{3} N-H A \\
& \text { TOA MA TOA - MA complex }
\end{aligned}
$$

This extracted acid by the amine extractant is generally known as an ammonium salt. The ion-pair formation complex occurs when Malic acid exists in the dilute aqueous phase in its dissociation form. The extent of association of the ion pair (acid radical and alkylammonium radical) leads to the quantification of extraction degree and stability ${ }^{6}$.

$$
\begin{array}{llll}
R_{3} N & +H^{+}+A^{-} & \leftrightarrow & R_{3} N^{+} A^{-} \\
\text {TOA } & \begin{array}{l}
\text { Malic acid } \\
\text { (dissociated form) }
\end{array} & \text { TOA }- \text { MAcomplex } \\
& &
\end{array}
$$

The hydrogen bond formation could also be possible between the complex $\mathrm{C}=\mathrm{O}$ of $(1: 1)$ trioctylamine-malic acid with 1-decanol which is present as a diluent in the oil phase ${ }^{39}$.

$$
\begin{array}{lcc}
\mathrm{R}_{3} \mathrm{NH}^{+} A^{-} & +\mathrm{C}_{10} \mathrm{H}_{21} \mathrm{OH} \leftrightarrow & R_{3} \mathrm{NH}^{+} A^{-} H^{+} \mathrm{OC}_{10} \mathrm{H}_{21} \\
\text { TOA }- \text { Acid complex } & \text { 1-Decanol } & \text { TOA-Acid-1 Decanol Complex }
\end{array}
$$

The malic acid reactive extraction process performance was assessed by the Extraction efficiency and Distribution coefficient $\left(\mathrm{K}_{\mathrm{D}}\right)$ at equilibrium as the ratio of the concentration of acid in the organic phase $[H A]_{o r g}$ to the concentration in aqueous phase $[H A]_{a q}$ as shown in "Eq. (13)" and "Eq. (14)".

$$
\begin{aligned}
& \text { Distribution coefficient }\left(\mathrm{K}_{\mathrm{D}}\right)=\frac{[H A]_{\text {org }}}{[H A]_{a q}} \\
& \text { Extraction efficiency }(\% \mathrm{E})=\frac{K_{D} \times 100}{1+K_{D}}
\end{aligned}
$$

Received: 13 August 2019; Accepted: 22 January 2020;

Published online: 12 February 2020

\section{References}

1. López-Garzón, C. S. \& Straathof, A. J. J. Recovery of carboxylic acids produced by fermentation. Biotechnology Advances 32 , 873-904, https://doi.org/10.1016/j.biotechadv.2014.04.002 (2014).

2. Zelle, R. M. et al. Malic acid production by Saccharomyces cerevisiae: engineering of pyruvate carboxylation, oxaloacetate reduction, and malate export. Appl. Environ. Microbiol. 74, 2766-2777 (2008).

3. Hulse, J. H. Biotechnologies: past history, present state and future prospects. Trends in food science \& technology 15, 3-18 (2004).

4. Straathof, A. The proportion of downstream costs in fermentative production processes. Comprehensive biotechnology 2, 811-814 (2011).

5. Datta, D., Kumar, S. \& Uslu, H. Status of the Reactive Extraction as a Method of Separation. Journal of Chemistry 2015 (2015).

6. Hong, Y., Hong, W. \& Han, D. Application of reactive extraction to recovery of carboxylic acids. Biotechnology and Bioprocess Engineering 6, 386-394, https://doi.org/10.1007/BF02932319 (2001).

7. Wasewar, K. L., Heesink, A. B. M., Versteeg, G. F. \& Pangarkar, V. G. Reactive extraction of lactic acid using alamine 336 in MIBK: equilibria and kinetics. Journal of Biotechnology 97, 59-68, https://doi.org/10.1016/S0168-1656(02)00057-3 (2002).

8. Wasewar, K. L. Separation of lactic acid: recent advances. Chemical and biochemical engineering quarterly 19, 159-172 (2005).

9. Wasewar, K. L., Shende, D. \& Keshav, A. Reactive extraction of itaconic acid using quaternary amine Aliquat 336 in ethyl acetate, toluene, hexane, and kerosene. Industrial \& Engineering Chemistry Research 50, 1003-1011 (2010).

10. Wasewar, K. L., Shende, D. \& Keshav, A. Reactive extraction of itaconic acid using tri-n-butyl phosphate and aliquat 336 in sunflower oil as a non-toxic diluent. Journal of chemical technology and biotechnology 86, 319-323 (2011).

11. Kurzrock, T. \& Weuster-Botz, D. New reactive extraction systems for separation of bio-succinic acid. Bioprocess and biosystems engineering 34, 779-787 (2011).

12. Eda, S., Parthasarathy, R. \& Prathap Kumar, T. Reactive Extraction of Succinic Acid from Aqueous Solutions using Tri-N-Octylamine (TOA) in 1-Decanol: Equilibria and Effect of Temperature. (2015).

13. Brouwer, T., Blahusiak, M., Babic, K. \& Schuur, B. Reactive extraction and recovery of levulinic acid, formic acid and furfural from aqueous solutions containing sulphuric acid. Separation and Purification Technology 185, 186-195, https://doi.org/10.1016/j. seppur.2017.05.036 (2017).

14. Kumar, T. P., Vishwanadham, B., Rani, K. P., Mallikarjun, M. \& Rao, V. B. Reactive extraction of levulinic acid from aqueous solutions with tri-n-octylamine (TOA) in 1-octanol: equilibria, kinetics, and model development. Chemical Engineering Communications 198, 572-589 (2010). 
15. Marti, M. E., Gurkan, T. \& Doraiswamy, L. K. Equilibrium and Kinetic Studies on Reactive Extraction of Pyruvic Acid with Trioctylamine in 1-Octanol. Industrial \& Engineering Chemistry Research 50, 13518-13525, https://doi.org/10.1021/ie200625q (2011).

16. Sharma, H., Singh, K., Wasewar, K. L. \& Athankar, K. K. L. -tartaric Acid Separations Using Aliquat 336 in n-Heptane. Kerosene, and 1-Octanol at $300 \pm 1 \mathrm{~K}$. Journal of Chemical \& Engineering Data 62, 4047-4063 (2017).

17. Keshav, A., Wasewar, K. \& Chand, S. Reactive extraction of propionic acid using tri-n-butyl phosphate in petroleum ether: Equilibrium study. Chemical and biochemical engineering quarterly 22, 433-437 (2008).

18. Keshav, A., Wasewar, K. L. \& Chand, S. Recovery of propionic acid from an aqueous stream by reactive extraction: effect of diluents. Desalination 244, 12-23, https://doi.org/10.1016/j.desal.2008.04.032 (2009).

19. Keshav, A., Wasewar, K. L. \& Chand, S. Recovery of propionic acid by reactive extraction-1. Equilibrium, effect of $\mathrm{pH}$ and temperature, water coextraction. Desalination and Water Treatment 3, 91-98 (2009).

20. Gorden, J., Zeiner, T. \& Brandenbusch, C. Reactive extraction of cis,cis-muconic acid. Fluid Phase Equilibria 393, 78-84, https://doi. org/10.1016/j.fluid.2015.02.030 (2015).

21. Han, D., Hong, Y. \& Hong, W. Separation characteristics of lactic acid in reactive extraction and stripping. Korean Journal of Chemical Engineering 17, 528-533, https://doi.org/10.1007/BF02707161 (2000).

22. Uslu, H. \& İsmail Kırbaşlar, S. Investigation of phase equilibria of levulinic acid distribution between aqueous phase to organic phase by Aliquat 336 in different modifiers. The Journal of Chemical Thermodynamics 41, 1042-1048, https://doi.org/10.1016/j. jct.2009.04.010 (2009).

23. Ratchford, W. P., Harris, E. H., Fisher, C., Willits, C. J. I. \& Chemistry, E. Extraction of lactic acid from water solution by aminesolvent mixtures. 43, 778-781 (1951).

24. Wennersten, R. The extraction of citric acid from fermentation broth using a solution of a tertiary amine. Journal of Chemical Technology and Biotechnology. Biotechnology 33, 85-94 (1983).

25. Bízek, V., Horáček, J. \& Koušová, M. Amine extraction of citric acid: effect of diluent. Chemical engineering science 48, 1447-1457 (1993).

26. Marinova, M., Albet, J., Molinier, J. \& Kyuchoukov, G. Specific influence of the modifier (1-decanol) on the extraction of tartaric acid by different extractants. Industrial \& engineering chemistry research 44, 6534-6538 (2005).

27. Kertes, A. S. \& King, C. J. Extraction chemistry of fermentation product carboxylic acids. Biotechnology and Bioengineering 28, 269-282, https://doi.org/10.1002/bit.260280217 (1986).

28. Tamada, J. A. \& King, C. J. Extraction of carboxylic acids with amine extractants. 2. Chemical interactions and interpretation of data. Industrial \& engineering chemistry research 29, 1327-1333 (1990).

29. Kumar, S. \& Babu, B. Reactive Extraction of Propionic Acid with Aliquat 336 Dissolved in 1-Decanol and n-Dodecane. J. Future Eng. Technol 3, 21-27 (2008).

30. Wasewar, K. L. Reactive extraction: an intensifying approach for carboxylic acid separation. International Journal of Chemical Engineering and Applications 3, 249 (2012).

31. Tamada, J. A. \& King, C. J. Extraction of carboxylic acids with amine extractants. 3. Effect of temperature, water coextraction, and process considerations. Industrial \& engineering chemistry research 29, 1333-1338 (1990).

32. Senol, A. Effect of diluent on amine extraction of acetic acid: modeling considerations. Industrial \& engineering chemistry research 43, 6496-6506 (2004).

33. Baş, D. \& Boyac1, I. H. Modeling and optimization I: Usability of response surface methodology. Journal of food engineering 78 , $836-845$ (2007).

34. Marchitan, N. et al. Modeling and optimization of tartaric acid reactive extraction from aqueous solutions: A comparison between response surface methodology and artificial neural network. Separation and Purification Technology 75, 273-285 (2010).

35. Li, D., Liu, X. \& Cui, J. Reactive Extraction of o-Aminophenol Using Trialkylphosphine Oxide1 1Supported by the Educational Department of Henan Province (No. 2004530001). Chinese Journal of Chemical Engineering 14, 46-50, https://doi.org/10.1016/ S1004-9541(06)60036-0 (2006).

36. Tang, K., Miao, J., Zhou, T. \& Liu, Y. Equilibrium Studies on Liquid-Liquid Reactive Extraction of Phenylsuccinic Acid Enantiomers Using Hydrophilic $\beta$-CD Derivatives Extractants. Chinese Journal of Chemical Engineering 19, 397-403, https://doi.org/10.1016/ S1004-9541(09)60227-5 (2011).

37. Qin, W., Li, Z. \& Dai, Y. Extraction of monocarboxylic acids with trioctylamine: equilibria and correlation of apparent reactive equilibrium constant. Industrial \& engineering chemistry research 42, 6196-6204 (2003).

38. Kumar, S., Datta, D. \& Babu, B. V. Estimation of equilibrium parameters using differential evolution in reactive extraction of propionic acid by tri-n-butyl phosphate. Chemical Engineering and Processing: Process Intensification 50, 614-622, https://doi. org/10.1016/j.cep.2011.03.004 (2011).

39. Wang, K. et al. Equilibrium study on reactive extraction of propionic acid with N1923 in different diluents. Fluid Phase Equilibria 278, 103-108 (2009).

40. Waghmare, M. D., Wasewar, K. L., Sonawane, S. S. \& Shende, D. Z. Reactive extraction of picolinic and nicotinic acid by natural non-toxic solvent. Separation and Purification Technology 120, 296-303 (2013).

41. Keshav, A., Chand, S. \& Wasewar, K. L. Equilibrium studies for extraction of propionic acid using tri-n-butyl phosphate in different solvents. Journal of Chemical \& Engineering Data 53, 1424-1430 (2008).

42. Zhang, P., Luo, J., Tang, K., Yi, J. \& Yang, C. Kinetics study on reactive extraction of dp-hydroxyphenylglycine by BINAP-palladium complex in Lewis cell. Chemical Engineering and Processing: Process Intensification 93, 50-55 (2015).

43. Poposka, F. A., Nikolovski, K. \& Tomovska, R. Kinetics, mechanism and mathematical modelling of extraction of citric acid with isodecanol/n-paraffins solutions of trioctylamine. Chemical Engineering Science 53, 3227-3237 (1998).

\section{Author contributions}

V.I. and D.L. conceived the experiment(s) and the experimental set up. V.I. conducted the experiments and analysed the results under the supervision of D.L. Both authors reviewed the manuscript.

\section{Competing interests}

The authors declare no competing interests.

\section{Additional information}

Supplementary information is available for this paper at https://doi.org/10.1038/s41598-020-59273-Z.

Correspondence and requests for materials should be addressed to V.I.

Reprints and permissions information is available at www.nature.com/reprints.

Publisher's note Springer Nature remains neutral with regard to jurisdictional claims in published maps and institutional affiliations. 
(c) (i) Open Access This article is licensed under a Creative Commons Attribution 4.0 International License, which permits use, sharing, adaptation, distribution and reproduction in any medium or format, as long as you give appropriate credit to the original author(s) and the source, provide a link to the Creative Commons license, and indicate if changes were made. The images or other third party material in this article are included in the article's Creative Commons license, unless indicated otherwise in a credit line to the material. If material is not included in the article's Creative Commons license and your intended use is not permitted by statutory regulation or exceeds the permitted use, you will need to obtain permission directly from the copyright holder. To view a copy of this license, visit http://creativecommons.org/licenses/by/4.0/.

(C) The Author(s) 2020 